\title{
LIII. On the proportion of nitrogen contained in alimentary substances taken from both the organic kingdoms as a comparative measure of their nutritive power
}

\section{Dr. J. Schlossberger \& Alexander Kemp}

To cite this article: Dr. J. Schlossberger \& Alexander Kemp (1845) LIII. On the proportion of nitrogen contained in alimentary substances taken from both the organic kingdoms as a comparative measure of their nutritive power, Philosophical Magazine Series 3, 27:181, 350-362, DOI: $10.1080 / 14786444508645297$

To link to this article: http://dx.doi.org/10.1080/14786444508645297

$$
\text { 曲 Published online: } 30 \text { Apr } 2009 .
$$

Submit your article to this journal ए

\section{щll Article views: 2}

Q View related articles ¿ 
observed facts go to prove that platinum reduces the gases to a state analogous to the nascent state, $i . e$. one at which their specific chemical energies are at the highest, but it does not change their specific energies; thus platinum enables gaseous oxygen to combine with gaseous hydrogen, but it does not give to oxygen the affinities of chlorine, or to hydrogen those of potassium. Even the granting this hypothesis, however, does not extricate us, as whatever specific power the platinum may possess in respect to the gas, it must also possess in respect to the electrolyte; it can scarcely be supposed to assist combination and yet not to prevent decomposition of the same molecule; it is an equation upon any view.

Nor can it be supposed that the action in the liquid of the gas battery cells differs from other cases of electrolysis; the line of discharge in the gas battery affects the magnet, and indeed forming portion of the voltaic circuit, it would be contrary to all analogy to suppose it exceptional in respect of its mode of action. An hypothesis might be framed which would regard the action of the gas battery as resulting from the formation of a soluble peroxide of hydrogen and perhydruret of oxygen; but if so, a similar hypothesis must be extended to all cases of electrolysis; and this view presents many difficulties. Perhaps some of your correspondents may be able to solve the theorem; for if not reconciled with facts, however: ingenious and useful the theory of Grotthus be, it is a theory, while the gas battery is a fact, and in case of collision, it is needless to say which must go to the wall.

$$
\begin{aligned}
& \text { I remain, my dear Sir, } \\
& \text { Yours very truly, } \\
& \text { W. R. Grove. }
\end{aligned}
$$

LIII. On the Proportion of Nitrogen contained in Alimentary Substances taken from both the Organic Kingdoms as a comparative measure of their Nutritive Power. By Dr. J. Schlossberger and Alexanden Kemp, Assistant Chemical Teachers in the University of Edinburgh*.

THE distinction between the elements of the reproductive and those of the respiratory functions, is probably one of the most fertile ideas for which physiology is indebted to modern chemistry; even if we do not admit that division in its full extent, nevertheless we must allow it to be a beautifully conceived idea, and one founded on a great amount of observation. It may be assumed with safety that no other classification of the substances comprised under the vague designation

* Communicated by the Authors. 
of alimentary bodies, has in an equal degree represented the essential differences in their chemical composition and their physiological effects, or has presented to the eye of the mind the important part which these substances perform, as the above-mentioned distinction, which is also identical with that of azotised and non-azotised bodies.

In order to give some indication of the state of confusion which existed, even in this most elementary proposition of dietetics, previous to that distinction being made, it may not be more than necessary to mention the idea of that classical author, Dr. Prout*, that the nutritive power is in direct proportion to the quantity of carbon. At the present day not a single fact is known which can support the idea of the animal body being able to form azotised from non-azotised substances, - possibly, under the influence of ammonia or of nitrogen from the atmosphere; on the contrary, all experiments, as well as daily observation, seem to prove the absolute necessity of azotised food for the preservation of the individual. Chemistry has likewise demonstrated the presence of a more or less high, but constant proportion of nitrogen in all the tissues and fluids of the animal body, while in all those substances which, according to our modern ideas, are the most nutritive, namely, the proteine compounds, the carbon is present in medium quantity. Those substances esteemed by Prout the most nourishing, because richest in carbon, as the fats and oils, must be altogether excluded from the list of reproductive bodies, except in so far as fatty matter is necessary to the formation of animal cells. The chemical physiologist could make use of the theory of Prout, in measuring the fitness of the bodies necessary to respiration, if along with the carbon could be taken into account the quantity of combustible or unoxidized hydrogen contained in them; but for those substances, which in the strict sense of the word are capable of being transformed into blood and animal tissue, according to our present knowledge, the capability for these purposes may be estimated relatively by the amount of nitrogen. This has been already done to a certain extent by the researches of several chemists and physiologists, but, so far as we are aware, it has been confined to vegetables; and it therefore appeared to us not to be without interest to make use of the same principle in extending the investigation to the various alimentary substances taken from the animal kingdom, and so to give to the physiologist a basis founded on facts in a de-

* See Mayo's Outlines of Human Physiology, p. 206, second edition. London, 1829. 
partment which has hitherto been so defective in the mysterious doctrine of nutrition.

Already Boussingault and Liebig have demonstrated, that in general the amount of proteine compound, and therefore that of nitrogen, is in a direct ratio to the phosphates; this proposition has as yet been extended only to vegetable matters, but will most probably preserve its value when applied likewise to those derived from animals. In so far as the nitrogen may be taken as an indication of the quantity of these salts, we could not find any observations as to how far it might be also applied to the gelatigenous compounds; and we have alluded to this as a very interesting field for future research, particularly with regard to the phosphate of lime, which seems so universal and so necessary to the whole animal oconomy.

It seems to be at present a proper time to overcome an objection, which, if not alluded to, might have been made against our attempt to determine the nutritive power of animal aliments; it is with regard to the delicate question of the use of animal gelatine, which seemed to Mulder, and likewise to us, as not at all decided by the experiments lately made at Paris. It is a fact sufficiently proved by the experiments of Magendie, Tiedemann and Gmelin, that any substance, even the most nourishing, if very simple and used without admixture, cannot sustain animal life for any length of time; and if it was proved at Paris that dogs fed exclusively on gelatine perish, it is far from being just to conclude that the substance is not nutritive, as we should be compelled to apply the same rule to albumen and fibrine, by the exclusive use of which an animal would no less speedily perish. At all events gelatine has a high value as nutriment, if even that value arises alone from its being useful in the formation of gelatigenous tissues; in addition, the gelatigenous tissues, as well as those containing proteine, in regard to their formation and chemical constitution, seem to lie in close relation, although that relation is at present not perfectly understood*. The experience of our best physicians at the bedside of the patient tends to prove that during convalescence a well-prepared gelatinous diet, but not exclusively gelatinous, is highly nutritious.

All organic alimentary substances, as presented to us by nature, are mixtures, but seem to be pretty constant in their composition, although variously modified by our different modes of cooking them. Of such natural mixtures, the greater part taken from vegetable bodies have already had the

* See Mulder's Chemistry of Animal and Vegetable Physiology, translated by Fromberg, 319 and following pages. 
proportion of nitrogen contained in them determined by pre. vious observers; and we believe we shall best introduce the subject by a concise representation of that which has been done in regard to the vegetable part of our aliments, which will likewise afford the best means of comparing the results of our experiments on animal substances.

The following table shows the amount of nitrogen contained in 100 parts of the dry vegetable bodies named in it:-

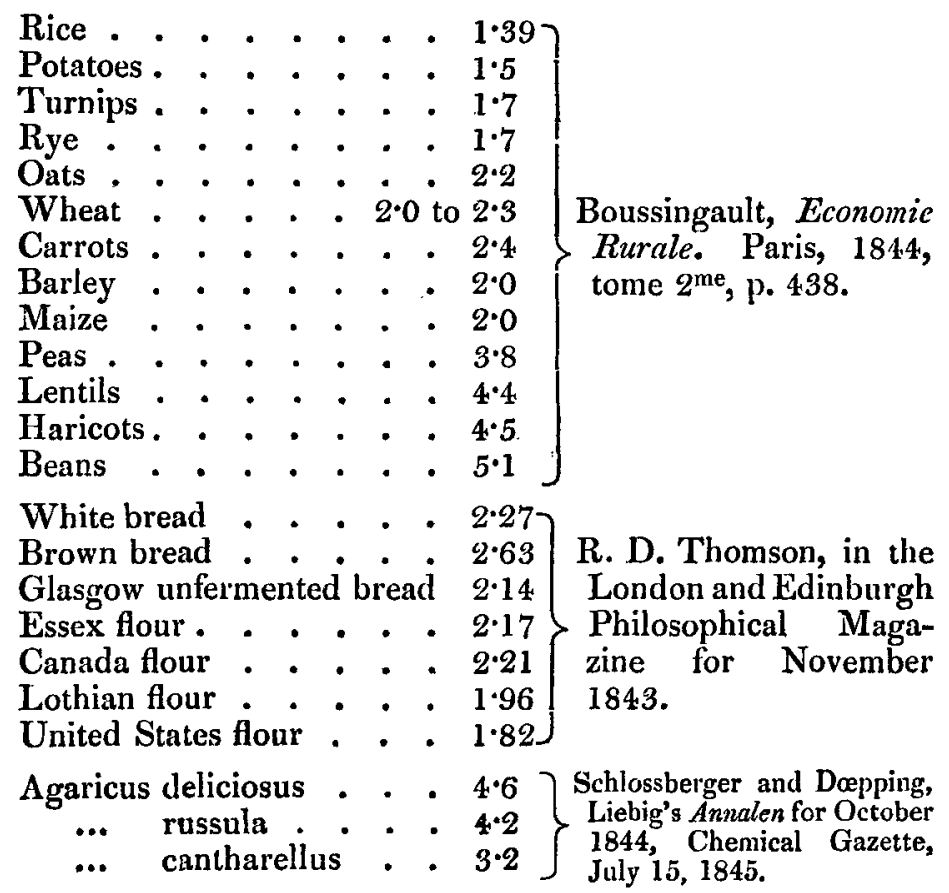

Boussingault has calculated from the results of his experiments, that which he calls the equivalent nutritive powers of these substances for the domestic herbivorous animals, and Thomson has also given one for those bodies which he examined. We omit these tables, as we have the intention of constructing a table of our own for all the substances which are used as food by man, and which have been hitherto examined in this respect.

We may now proceed to the relation of our experiments. All the substances made the subject of observation were first carefully dried at $212^{\circ} \mathrm{F}$, and then analysed according to the method of Varrentrapp and Will, slightly modified to overcome some practical difficulties.

Phil. Mag. S. 3. Vol. 27. No. 181, Nov. 1845. 


\section{Messrs. Schlossberger and Kemp on the Proportion of}

Intermediate between animal and vegetable aliment, as daily observation teaches and chemical analysis confirms, is to be found the most general food of the young of the class Mammalia, namely, milk.

I. Cow's milk. 0.404 gramme* of the dried residue, obtained by evaporating the fresh-drawn milk in the water-bath and subsequent desiccation at $212^{\circ} \mathrm{F}$., yielded 0.241 grm. of the ammonio-chloride of platinum, corresponding to $3 \cdot 78$ per cent. of nitrogen.

II. $0.438 \mathrm{grm}$. human milk, treated as in the first experiment, gave $0.11 \mathrm{grm}$. ammonio-chloride of platinum, equal to 1.59 per cent. of nitrogen.

Human milk is, according to most analyses, one of the poorest in caseine, and in this respect is very far inferior to that of the cow, but in consequence of this may probably be more easily digested. The amount of nitrogen in milk, which corresponds to that of caseine, comes much nearer to the proportion contained in vegetables than any other kind of aliment from the animal kingdom.

Of the substances obtained from milk and used as food, we have examined only that of cheese, selecting four of the kinds most commonly used in Britain.

III. 0:485 grm. of Dunlop cheese gave $0.461 \mathrm{grm}$. of ammonio-chloride of platinum, equal to 6.03 per cent. of nitrogen.

IV. $0.475 \mathrm{grm}$. of Gouda cheese gave $0.532 \mathrm{grm}$. of ammonio-chloride of platinum, equal to $7 \cdot 11$ per cent. of nitrogen.

V. $0.444 \mathrm{grm}$. of Cheshire cheese gave $0.471 \mathrm{grm}$. of ammonio-chloride of platinun, equal to 6.75 per cent. of nitrogen.

VI. 0.477 grm. of double Gloucester cheese gave 0.525 grm. of ammonio.chloride of platinum, equal to 6.98 per cent. of nitrogen.

VII. $0.557 \mathrm{grm}$. of a very old double Gloucester cheese, abounding in mites and mould, in the condition in which it is sought after to gratify the depraved taste of the epicure, gave $0.463 \mathrm{grm}$. of ammonio-chloride of platinum, equal to 5.27 per cent. of nitrogen.

We add here, as being similar in composition, the yolk of the egg of the common fowl:

VIII. $0.526 \mathrm{grm}$. of well-dried yolk gave $0.387 \mathrm{grm}$. of ammonio chloride of platinum, equal to $4 \cdot 86$ per cent. of nitrogen.

* The balance used in these analyses having been made by Deleuil of Paris, and being only furnished with French weights, will account for the introduction of the word here, and in the other analyses throughout the paper. The French gramme is equal to 15.444 English grains. 
Somewhat more nutritive than milk, and more nearly allied to cheese, is a series of bodies obtained from the lower orders of the animal kingdon. We give here, as examples, the oyster and one or two others.

IX. $0.418 \mathrm{grm}$. of the oyster, Ostrea edulis, gave 0.346 grm. of ammonio-chloride of platinum, equal to $5^{\cdot 25}$ per cent. of nitrogen.

As this seemed to us a very low result, we repeated our analysis, which, however, confirmed our first experiment; in this case 0.354 grm. giving $0.283 \mathrm{grm}$. of ammonio-chloride, of platinum, equal to 5.07 per cent. of nitrogen.

$X$. 0.354 grm. of the yellow matter (liver and bile) from the crabfish, Cancer communis, gave $0.418 \mathrm{grm}$. of ammoniochloride of platinum, equal to $7 \cdot 52$ per cent. of nitrogen.

XI. $0.377 \mathrm{grm}$. of the common mussel, Mytilus edulis, gave $0.498 \mathrm{grm}$. of ammonio-chloride of platinum, equal to 8.41 per cent. of nitrogen.

XII. $0.308 \mathrm{grm}$. of the above animal, previously boiled, gave $0.510 \mathrm{grm}$. of ammonio-chloride of platinum, equal to 10.51 per cent. of nitrogen.

We find that many of the organs of the higher animals, for example, the liver of the ox, nearly agree in the amount of nitrogen with those substances we have just treated of.

XIII. $0.4 .32 \mathrm{grm}$. of ox liver gave $0.726 \mathrm{grm}$. of ammoniochloride of platinum, equal to $10^{\circ} 66$ per cent. of nitrogen.

XIV. $0.419 \mathrm{grm}$. of the liver of the pigeon gave $0.778 \mathrm{grm}$. of ammonio-chloride of platinum, equal to 11.80 per cent, of nitrogen.

For the reason just mentioned, we here likewise notice the analysis of the muscles of some kinds of fish, which, from being quite saturated with oil, give a low amount of nitrogen; for instance, that of the eel containing 6.91 per cent., and pork ham, from the large quantity of salt, giving only 8.57 per cent.; but we shall return to these more in detail. The connecting link between the two extremities of the nutritive scale of animal aliments we have formed, appears to be the dried extract of meat, which is sold under the name of portable soup, or bouillon.

XV. $0.44 \mathrm{I}$ grm. of portable soup, of an excellent quality, gave $0.845 \mathrm{grm}$. of ammonio-chloride of platinum, equal to $12 \cdot 16$ per cent. of nitrogen. Osmazome is therefore a body rich in nitrogen, probably from containing oxide of proteine, and perhaps also kreatine.

We shall give our results on the different kinds of flesh, including that of the fishes also, with which we begin.

Common eel, Anguilla vulgaris.-The flesh of this fish is 2 A 2 
poorer in nitrogen than any of the others which we have examined, in consequence of the large quantity of fat or oil it contains; indeed, during the whole desiccation it was floating in a liquid fat.

XVI. $0.345 \mathrm{grm}$. of raw eel's flesh gave $0.379 \mathrm{grm}$. of ammonio-chloride of platinum, equal to 6.91 per cent. of nitrogen.

XVII. $0.306 \mathrm{grm}$. of boiled eel's flesh gave $0.329 \mathrm{grm}$. of ammonio-chloride of platinum, equal to 6.82 per cent. of nitrogen.

XVIII. 0.293 grm. of eel's flesh, which had been previously washed with distilled water and afterwards boiled in alcohol as long as any matter separated, yielded 0.667 grm. of ammonio-chloride of platinum, equal to $14 \cdot 4.5$ per cent. of nitrogen, a quantity as great as that from the higher animals.

XIX. 0.274 grm. of the flesh of the salmon, Salmo Fario, gave $0.533 \mathrm{grm}$. of ammonio-chloride of platinum, equal to 12.35 per cent. of nitrogen.

XX. $0.286 \mathrm{grm}$. of boiled salmon gave $0.437 \mathrm{grm}$. of ammonio-chloride of platinum, equal to $9 \cdot 70$ per cent. of nitrogen.

XXI. $0.319 \mathrm{grm}$. of the purified muscular fibre of the salmon gave $0.785 \mathrm{grm}$. of ammonio-chloride of platinum, equal to 15.62 per cent. of nitrogen.

XXII. $0.271 \mathrm{grm}$. of the raw herring, Clupea Harengus, gave $0.590 \mathrm{grm}$. of ammonio-chloride of platinum, equal to 14.48 per cent. of nitrogen.

XXIII. $0.314 \mathrm{grm}$. of boiled herring gave $0.636 \mathrm{grm}$. of ammonio-chloride of platinum, equal to $12: 85$ per cent. of nitrogen.

XXIV. $0.350 \mathrm{grm}$. of purified muscle of the herring gave $0.802 \mathrm{grm}$. of ammonio-chloride of platinum, equal to 14.54 per cent. of nitrogen.

XXV. $0.4065 \mathrm{grm}$. of the milt of the herring gave 0.940 grm. of ammonio-chloride of platinum, equal to 14.69 per cent. of nitrogen. This substance is therefore as nutritive as the muscular parts of the fish, containing the same amount of nitrogen.

XXVI. 0.316 grm. of the flesh of the haddock, Eglefinus communis, gave $0.729 \mathrm{grm}$. of ammonio-chloride of platinum, equal to $14^{\cdot 64}$ per cent. of nitrogen.

XXVII. $0.331 \mathrm{grm}$. of boiled haddock gave $0.677 \mathrm{grm}$. of ammonio-chloride of platinum, equal to 12.98 percent. of nitrogen. Whereas in the case of the herring, salmon, haddock, and eel, the proportion of nitrogen was considerably diminished 
by boiling the flesh for about half an hour, the reverse of this occurred in some of the other cases ; for example, in the mussel, the flesh of the ox and calf. These are mere observations of facts, arising probably from accidental causes; the modification which meat undergoes by boiling not being sufficiently understood by chemists at present, although Mulder has proved the formation of oxide of proteine by it; from the observations just made, no general conclusion can be drawn, because they do not seem to coincide, at least at first sight.

XXVIII. 0.271 grm. of the purified muscle of the haddock gave $0.671 \mathrm{grm}$. of ammonio-chloride of platinum, equal to $15 \cdot 72$ per cent. of nitrogen.

XXIX. $0.348 \mathrm{grm}$. of the flesh of the flounder, Platessa Flessus, gave $0.783 \mathrm{grm}$. of ammonio-chloride of platinum, equal to 14.28 per cent. of nitrogen.

XXX. $0.34 .2 \mathrm{grm}$. of boiled flounder gave $0.818 \mathrm{grm}$. of ammonio-chloride of platinum, equal to $15^{\circ} 18$ per cent. of nitrogen.

XXXI. $0.301 \mathrm{grm}$. of purified muscle of the flounder gave $0.74 .5 \mathrm{grm}$. of ammonio-chloride of platinum, equal to 15.71 per cent. of nitrogen.

We have selected the skate, Raia Batis, as a fair example of the cartilaginous order of fishes.

XXXII. $0.415 \mathrm{grm}$. of the flesh of the skate gave $1 \cdot 066$ grm. of ammonio-chloride of platinum, equal to $15^{\circ} 39$ per cent. of nitrogen.

XXXIII. 0.402 grm. of boiled skate gave 0.964 grm. of ammonio-chloride of platinum, equal to $15^{\circ} 22$ per cent. of nitrogen.

XXXIV. 0.407 grm. of the boiled muscle taken from the claw of the crabfish gave $0.877 \mathrm{grm}$. of ammonio-chloride of platinum, equal to 13.66 per cent. of nitrogen. From this analysis we are led to believe that the muscles of the Crustacea are as rich in nitrogen as those of much more highly organised animals.

XXXV. $0.299 \mathrm{grm}$. of the flesh of the pigeon gave 0.570 grm. of ammonio-chloride of platinum, equal to $12 \cdot 10$ per cent. of nitrogen. This is a surprisingly low number, more especially as the muscle of this bird was nearly free of fat.

XXXVI. 0.334 grm. of boiled pigeon gave $0.649 \mathrm{grm}$. of ammonio-chloride of platinum, equal to $12 \cdot 33$ per cent. of nitrogen.

XXXVII. $0.166 \mathrm{grm}$. of the purified muscle of the pigeon gave $0.344 \mathrm{grm}$. of ammonio-chloride of platinum, equal to 13.15 per cent. of nitrogen. The fibre used in this experi- 
ment most tenaciously retained a small quantity of the colouring matter of the blood. We have already given the analysis of the liver of this bird (experiment XIV.).

XXXVIII. $0.347 \mathrm{grm}$. of lamb gave $0.725 \mathrm{grm}$. of ammonio-chloride of platinum, equal to 33.26 per cent. of nitrogen.

XXXIX. $0.320 \mathrm{grm}$. of the purified fibre of lamb gave $0.734 \mathrm{grm}$. of ammonio-chloride of platinum, equal to 14.56 per cent. of nitrogen.

XL. $0.336 \mathrm{grm}$. of mutton gave $0.651 \mathrm{grm}$. of ammoniochloride of platinum, equal to $12 \cdot 30$ per cent. of nitrogen. In this case it was found extremely difficult to separate mechanically the whole of the fat: it is necessary to notice this, as the numbers are somewhat lower than might have been expected.

XLI. $0.341 \mathrm{grm}$. of boiled mutton gave $0.728 \mathrm{grm}$. of ammonio-chloride of platinum, equal to 13.55 per cent. of nitrogen.

XLII. $0.335 \mathrm{grm}$. of the purified fibre from mutton gave $0.779 \mathrm{grm}$. of ammonio-chloride of platinum, equal to 14.76 per cent. of nitrogen.

XLIII. $0.318 \mathrm{grm}$. of veal gave $0.696 \mathrm{grm}$. of ammoniochloride of platinum, equal to 13.89 per cent. of nitrogen.

XLIV. $0.379 \mathrm{grm}$. of boiled veal gave $0.866 \mathrm{grm}$. of ammonio-chloride of platinum, equal to 14.50 per cent. of nitrogen.

XLV. 0.214 grm. of purified fibre from veal gave 0.532 grm. of ammonio-chloride of platinum, equal to $15 \cdot 78$ per cent. of nitrogen.

XLVI. $0.306 \mathrm{grm}$. of ox-beef gave $0.675 \mathrm{grm}$. of ammoniochloride of platinum, equal to 14.00 per cent. of nitrogen.

XLVII. Last experiment repeated. 0.292 grm. gave $0.633 \mathrm{grm}$. of ammonio-chloride of platinum, equal to 13.73 per cent. of nitrogen.

XLVIII. $0.331 \mathrm{grm}$. of boiled beef gave $0.781 \mathrm{grm}$. of ammonio-chloride of platinum, equal to 14.98 per cent of nitrogen.

XLIX. $0.392 \mathrm{grm}$. of purified fibre of beef gave 0.919 grm. of ammonio-chloride of platinum, equal to 14.88 per cent. of nitrogen. The liver of the ox gave $10^{\circ} 66$ per cent. of nitrogen (see XIII.).

L. $0.216 \mathrm{grm}$. of the lungs of the ox gave $0.504 \mathrm{grm}$. of ammonio-chloride of platinum, equal to $14 \cdot 81 \mathrm{per}$ cent. of nitrogen.

LI. $0.359 \mathrm{grm}$. of pork-ham gave $0.485 \mathrm{grm}$. of ammoniochloride of platinum, equal to 8.57 per cent. of nitrogen.

LII. $0.395 \mathrm{grm}$. of the boiled pork-ham gave $0.777 \mathrm{grm}$. 
of ammonio-chloride of platinum, equal to $12 \cdot 4.8$ per cent. of nitrogen.

LIII. 0.384 grm. of the purified fibre of pork-ham gave $0.860 \mathrm{grm}$. of ammonio-chloride of platinum, equal to $14 \cdot 21$ per cent. of nitrogen.

We regret that at the time when these experiments were made, we were unable to procure fresh pork, but we thought that an examination of the salted and smoked substance would not be devoid of interest.

From these results we see that there is no appreciable change produced in the composition of the fibre by the preparation and length of time it had been kept; if however we take equal weights of the prepared ham and of the fresh flesh of the sow, we shall of course find a considerable difference in the amount of nitrogen from the large quantity of salt which is present in the prepared ham. We conclude this account of our experiments by giving the analysis of the white of the egg of the barn-door fowl.

LIV. $0.369 \mathrm{grm}$. of the white of the egg gave $0.781 \mathrm{grm}$. of ammonio-chloride of platinum, equal to $13 * 44$ per cent. of nitrogen. The quantity of nitrogen in pure albumen, as determined by Mulder, is $15^{\circ} 8$ per cent.

We take the liberty to add to these experiments the following remarks :- The proportion of nitrogen in purified muscular fibre seems to be identical, from whatever part of the animal kingdom it may be obtained; and the differences given by the results of analysis may be fully explained by the diffculty, or even impossibility, of analysing it in an equally pure or impure condition, as obtained from different animals, in which it is always mixed with cellular tissue, minute vessels and nerves. Moreover, it is extremely difficult to get rid of traces of fat and hematine.

That the chemical properties of muscular fibre in the whole animal kingdom are identical, one of us endeavoured to prove in a former research (Schlossberger, Vergleichende Untersuchungen uber das Fleisch verschiedener Thiere. Stuttgardt, 1840). In contradiction to a very generally-received opinion, it appears to us that the muscles of fish are as rich in nitrogen as those of higher animals; at first sight, however, owing to the presence of a greater quantity of water, and in some fishes, as the eel, to a difficultly separable fat, its amount appears very much lower. Further, as the proximate principles are essentially the same in both classes of animals, it seems to us that they should be equally nutritive, although this proposition is also directly opposed to another very general prejudice. According to our scale, the oyster does not seem 
nearly so nourishing as it is generally reputed to be by conmon opinion, although it is possible that the proteine compounds in the lower classes of animals may be found to be much richer in phosphorus, in sulphur, and in phosphates than in the higher. Should this prove to be the case, we can see, that although the proportion of nitrogen may not be so great, nevertheless that they might act more powerfully as stimulants, which, as regards the oyster, is believed by some of our best physicians. We intend in a future series of experiments to direct our attention to this part of the subject.

In order that our views on this subject should not be misunderstood, it is necessary for us to state, that we do not consider the proportion of nitrogen, taken alone, to be an absolute measure of the nutritive power of our aliments; but as there is a total want of any positive data in regard to this subject, and as so many different and contradictory opinions are given in the works on dietetics*, it must be granted that any attempt to fix a standard for comparison is not without interest.

With respect to the capability for nutrition, we are far from denying that the physical condition, the state of admixture, the peculiar kind of proteine compound, the amount of water and other inorganic matters, of fat, and lastly, the effects of cookery, must necessarily have a very great influence on the physiological effects of our aliments.

There is one consideration in particular which requires to be noticed, namely the distinction between the absolute amount of nutritive matter and that portion of it which is in such a state as to be easily digested and assimilated by the system, in the same way as a soil produced from minerals abounding in alkaline salts is not always the most fertile as regards plants with a predominance of alkaline bases, but the fertility of which depends on the amount of these bodies contained in a state in which they can be taken up and made use of by the plant. Thus an aliment abounding in nutritive matter may be inferior to one with a much smaller quantity as regards the nourishing effects produced by it; if in the first of these cases only a part, in the second the whole may be easily absorbed and assimilated. Here we must rely upon the experiments of the physiologist as to the degree of digestibility of different substances; and there already exists an excellent basis in the researches of Beaumont and of Blondlot. This is one of the questions, in which, by the co-operation alone of the physiologist and chemist, any progress can be expected to be made

* See all works from Plenk's Bromatologia to the latest, as Paris's Treatise on Diet, as well as our standard works on Materia Medica, and we think it will be allowed that we have not asserted too much. 
in the elucidation of this point. If the work were once fairly begun by the physiologist, chemistry would not be long in rendering that assistance which would then be found necessary; for example, in the various experiments which might be made in artificial digestion, from the results of which as one element in the calculation taken along with the proportion of nitrogen as the other, it would at once be possible to determine scientifically the real nutritive value of the different kinds of aliment; the importance to our dietetics of this method of determination, which at present exists only in idea, would then not only be felt by the patient, but by the whole human race.

Table of the comparative proportion of nutriment in our organic aliments. If we assume the amount of nitrogen in human milk, perfectly dried at $212^{\circ} \mathrm{F}$, to be represented by 100 , we can then express the degree of nutritive power of the other alimentary substances by the following numbers:-

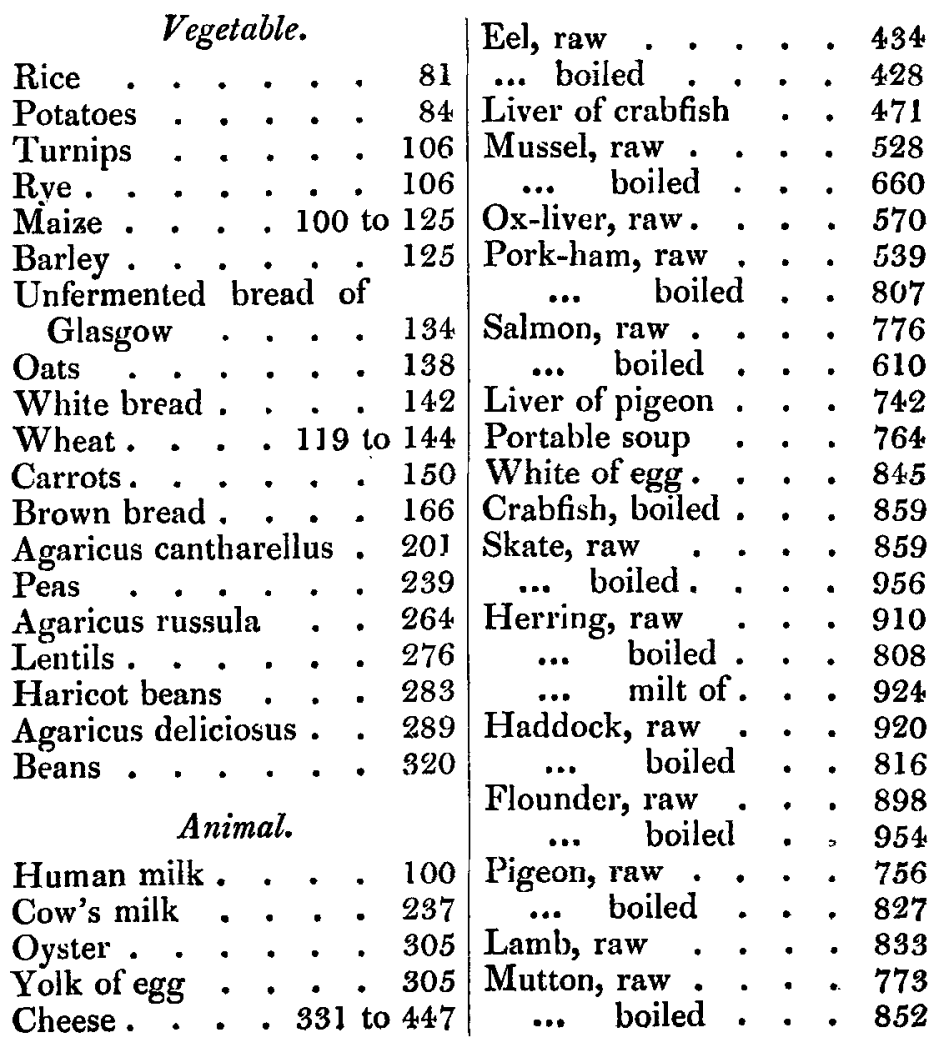


Animal (continued).

Fibre of sheep . . . 928

Veal, raw . . . . . $873 \quad$... $\quad$ calf . . . . 993

... boiled . . . . 911 ... $0 x$. . . . 935

Beef, raw . . . . $880 \quad$... sow . . . . 899

... boiled . . . . 942

Ox-lung . . . . 931

Proximate principles of animals, calculated from the quantity of nitrogen as determined by Mulder.

Fibre of eel . . . . 908

Pure proteine . . . 1006

... salmon . . . 982 ... albumen . . . 996

... herring. . . 914 ... fibrine . . . . 999

... haddock . . 988 ... caseine . . . . 1003

... flounder . . 988 ... gelatine . . . . 1128

... pigeon . . . 775 lamb chondrine . . . 910

LIV. On the Evaluation of the Sums of Neutral Series. By J. R. Young, Professor of Mathematics in Belfast College*.

THE attention of several analysts has been called of late to 1 the series $1-1+1-1+1 \ldots . .$. , and the long-prevailing doctrine that the sum of this series to infinity is necessarily $\frac{1}{2}$, is beginning to be questioned, and the true character of it to be recognised. There is danger however of mistake arising in another direction, for it has been affirmed that this series cannot be $\frac{1}{2}$, even when regarded as the limit of the converging cases of the general series $1-x+x^{2}-x^{3}+x^{4} \ldots$ It is my wish in the present communication to point out the error of this statement, and to notice the circumstances which appear to have led to it.

And in the first place I would observe, that when the series in question is intended to represent that which the general converging series becomes in the extreme case of $x=1$, it is considered as identical with $1-1+1^{2}-1^{3}+1^{4} \ldots \ldots 1^{\text {wi }}$, or rather,-indicating more explicitly the connexion of this extreme case with the general series of converging cases that it terminates, -it is considered as identical with

$1-\left(1-\frac{1}{\infty}\right)+\left(1-\frac{1}{\infty}\right)^{2}-\left(1-\frac{1}{\infty}\right)^{3}+\cdots\left(1-\frac{1}{\infty}\right)^{\infty}$.

Again, the general expression for $n$ terms of the series $1-x$

- Communicated by the Author, 